\title{
Potential drug interactions in drug therapy prescribed for older adults at hospital discharge: cross-sectional study
}

\author{
Bianca Menezes Dias', Fabiana Silvestre dos Santos", Adriano Max Moreira Reis"II \\ School of Pharmacy, Universidade Federal de Minas Gerais, Belo Horizonte (MG), Brazil
}

Pharmacist, School of Pharmacy, Universidade Federal de Minas Gerais (UFMG), Belo

Horizonte (MG), Brazil.

(D) orcid.org/0000-0002-8842-3643

"MSc. Pharmacist, School of Pharmacy, Universidade Federal de Minas Gerais (UFMG), Belo Horizonte (MG), Brazil.

(D) orcid.org/0000-0002-6551-4403

I'PhD. Associate Professor, Department of Pharmaceutical Products, School of Pharmacy, Universidade Federal de Minas Gerais (UFMG), Belo Horizonte (MG), Brazil.

(D) orcid.org/0000-0002-0017-7338

\section{KEY WORDS:}

Drug interactions.

Frail elderly.

Patient discharge.

Drug therapy.

\begin{abstract}
BACKGROUND: Older adults with a range of comorbidities are often prescribed multiple medications, which favors drug interactions.

OBJECTIVES: To establish the frequency of potential drug interactions in prescriptions at hospital discharge among older adults and to identify the associated factors.

DESIGN AND SETTING: Cross-sectional study conducted in a public hospital.

METHODS: An initial face-to-face interview, data collection from the electronic medical records (covering sociodemographic, clinical, functional and drug therapy-related variables) and telephone follow-up after discharge were conducted to confirm the medication prescribed at discharge. Drug interactions were identified through the Micromedex DrugReax software, along with interactions that should be avoided among the elderly, as per the 2015 American Geriatric Society/Beers criteria. Multivariable logistic regression was performed.

RESULTS: Potential for drug interactions was identified in the discharge drug therapy of $67.8 \%$ of the 255 older adults evaluated $(n=172)$, and $54.5 \%(n=145)$ of the drug interactions were major. Among the drug interactions that should be avoided among older adults, those that increase the risk of falls were the most frequent. The drug interactions thus identified were independently associated with polypharmacy (odds ratio, $\mathrm{OR}=12.62 ; 95 \%$ confidence interval, $\mathrm{Cl} 6.25-25.50 ; \mathrm{P}=0.00)$, diabetes mellitus $(\mathrm{OR}=2.16 ; 95 \% \mathrm{Cl}$ 1.05-4.44; $\mathrm{P}=0.04)$, hypothyroidism $(\mathrm{OR}=7.29 ; 95 \% \mathrm{Cl} 2.03-26.10 ; \mathrm{P}=0.00)$, chronic kidney disease $(\mathrm{OR}=3.41 ; 95 \% \mathrm{Cl}$ 1.09-10.64; $\mathrm{P}=0.03)$ and hospitalization in geriatric units $(\mathrm{OR}=0.45 ; 95 \% \mathrm{Cl} 0.22-0.89 ; \mathrm{P}=0.02)$.

CONCLUSION: The frequency of potential drug interactions in drug therapy prescribed at discharge for these older adults was high. Polypharmacy, diabetes mellitus, hypothyroidism and chronic kidney disease were positively associated with occurrences of drug interactions, while hospitalization in geriatric units showed an inverse association.
\end{abstract}

\section{INTRODUCTION}

The number of older adults in the world is expanding rapidly as a consequence of increased quality of life and technological advances. ${ }^{1,2}$ This demographic transition is increasing the prevalence of chronic-degenerative diseases. One of the consequences is higher consumption of medicines, which implies a great challenge for the healthcare system. ${ }^{3}$

Given that use of several drugs is needed to treat the multimorbidity commonly seen in older adults, it can be expected that the prevalence of polypharmacy among older adults and the risk of drug interactions will increase substantially. ${ }^{4}$ Drug interactions are a common cause of adverse drug reactions among older adults, and these include arrhythmias, acute kidney injury and increased risk of falls. ${ }^{5-7}$ A direct correlation between the number of medications and their interactions and the risk of adverse drug reactions has been shown. ${ }^{4-7}$ The reasons for this are multifactorial and particularly include age-related changes in the pharmacodynamics and pharmacokinetics of drugs, reduced renal function and lower hepatic clearance. ${ }^{6-8}$

At hospital discharge, older adults generally present changes to their drug therapy, with higher numbers of prescribed medications, which leads to higher frequency of drug interactions. ${ }^{8}$ Thus, it is essential to know the frequency of these interactions at hospital discharge among older people and their determinants, in order to promote safer use of drugs among older adults.

\section{OBJECTIVE}

The aims of this study were to determine the frequency of potential drug interactions in the drug therapy prescribed at discharge among older adults and to evaluate the factors associated with this outcome. 


\section{METHODS}

\section{Study design and setting}

This was a cross-sectional study carried out in a public hospital located in southeastern Brazil that is responsible for attending public servants. The hospital provides medium and high-complexity levels of care.

\section{Sample}

The sample was non-probabilistic, covering older inpatients admitted from April to November 2017. Age $\geq 60$ years was adopted to define older adults, as established by the World Health Organization for developing countries.

\section{Selection criteria}

This study included older patients hospitalized in the internal medicine and geriatric units over the period from April 4 to November 1, 2017. All patients who were hospitalized for more than 24 hours during the period of the investigation at the hospital were invited to participate in the research. The exclusion criteria were defined as occurrences of death during hospitalization, hospitalization for more than 60 days, self-discharge from the hospital or loss of contact after discharge.

\section{Data collection and ethics}

The patients were identified through the computerized system for hospitalization management of the hospital and were approached in person, in the hospital. All patients or their legal guardians gave their agreement to participate by signing an informed consent statement. This study was approved by the research ethics committee of Universidade Federal de Minas Gerais under the approval number 1.952.130.

An interview was conducted with patients to collect sociodemographic information. Clinical information was collected by consulting the patients' electronic medical record. The interviews and data collection were performed by a pharmacist researcher and recorded in the structured form. The pharmacist researcher also made a telephone follow-up within 48 hours after discharge in order to confirm which medications had been prescribed. The medications prescribed were registered on the structured form.

The dependent variable was the presence of potential drug interactions between the drugs prescribed at hospital discharge, using the data collected from the medical records and the confirmations from the telephone interviews. These potential drug interactions were identified using the IBM Micromedex DrugReax software, ${ }^{9}$ considering the medications prescribed at discharge and confirmed during the telephone contact. DrugReax presents adequate sensitivity and specificity for identifying drug interactions within older adults' drug therapy. ${ }^{10}$
Drug interactions were classified regarding their severity, adopting the DrugReax specifications: contraindicated (when the medications are contraindicated for concomitant use); major (when the interaction may be life-threatening for the patient and requires immediate medical intervention); or moderate (when the interaction may result in exacerbation of the patient's clinical condition or require a change of therapy). ${ }^{9}$ This investigation did not include the interactions defined by DrugReax as minor (when the interaction may have limited clinical effects without requiring drug therapy changes) or unknown effects (when the level of severity of the interaction is undefined). ${ }^{9}$

The dose of acetylsalicylic acid (ASA) was observed for the purpose of identifying the interactions involving this drug. For specific interactions involving ASA, the clinical management section of the DrugReax software informs whether this occurs with doses used for analgesia and antipyresis (> $300 \mathrm{mg}$ ) or doses used for antiplatelet effect (70-300 mg). ${ }^{9}$ Furthermore, the frequency of potential clinically-relevant drug interactions with non-anti-infective agents that should be avoided among the older adults, as per the 2015 American Geriatric Society (AGS)/Beers criteria, ${ }^{11}$ was established.

The demographic, clinical, functional and drug therapy-related independent variables of these older individuals were collected through interviews conducted during their hospitalization. These data were complemented through a search in each patient's medical records.

Presence of polypharmacy was defined as use of five or more medications. Admission diagnoses were classified in accordance with the International Classification of Diseases, $10^{\text {th }}$ edition (ICD-10). ${ }^{12}$ The patients were assessed using the Charlson Comorbidity Index (CCI). ${ }^{13}$ The complexity of the drug treatment regimen prescribed at discharge was determined by calculating the Medication Regimen Complexity Index (MRCI), using the Brazilian version. ${ }^{14}$ The drug therapy complexity was stratified as high $(\mathrm{MRCI}$ value $>16.5)$ or not high $(\mathrm{MRCI} \leq 16.5)$, as per the MRCI standardization proposed for Brazilian older adults. ${ }^{1}$ The patients' vulnerability was evaluated by means of the Vulnerable Elders Survey-13 tool (VES-13). ${ }^{16}$

\section{Statistical analysis}

The data collected were double-entered into a dataset elaborated in EpiData 3.1. The statistical analyses were performed using the Statistical Package for the Social Sciences (SPSS) 25.0 software.

Absolute and relative frequencies were determined for dichotomous variables, and numerical variables were described in terms of their mean (with standard deviation, SD) or median (with interquartile range, IQR). The Shapiro-Wilk test was used to assess whether the data presented normal distribution. Numerical variables were dichotomized using the median. Associations between independent variables and occurrences of drug interactions were 
evaluated using the chi-square test and Fisher's exact test, with due regard to the premises of each test.

The level of statistical significance of the study was considered to be $\mathrm{P}<0.05$. Variables with $\mathrm{P}<0.20$ in univariate analysis were included in the multivariate analysis through the logistic regression model. The forward stepwise method was used to obtain the final model, and variables presenting $\mathrm{P}<0.05$ were kept in the model. The goodness of fit of the final model was evaluated using the Hosmer-Lemeshow test, such that $\mathrm{P}>0.05$ was considered to indicate good logistic regression model fit.

\section{RESULTS}

In total, 300 older adults were interviewed. Among these, 27 (9\%) died during hospitalization, one $(0.3 \%)$ self-discharged from the hospital, one $(0.3 \%)$ was transferred to another hospital and three (1\%) were excluded due to prolonged hospitalization, since the duration of data collection was limited. Out of the 268 elderly subjects who were discharged, 13 (4.3\%) were subsequently lost to contact. Thus, 255 older people were included in this study (Figure 1).

The sample had a median age of 75 years (IQR 13.0) and consisted mostly of women (57.3\%). The median score in the Charlson Comorbidity Index was 5.0 (IQR 2.0), and the median score in the Vulnerable Elders Survey-13 (VES-13) was 5.0 (IQR 6.0).

Among the participating older adults, 158 (62.0\%) were hospitalized in the internal medicine unit and 97 (38.0\%) in the geriatric unit. The median length of hospital stay was 12 days (IQR 10). The most frequent admission diagnoses were respiratory system diseases $(64 ; 25.1 \%)$, genitourinary system diseases $(43 ; 16.9 \%)$ and circulatory system diseases $(30 ; 11.8 \%)$. The most frequent comorbidities among the elderly subjects were arterial hypertension $(\mathrm{n}=181 ; 71.0 \%)$, diabetes mellitus $(\mathrm{DM})(\mathrm{n}=110 ; 43.1 \%)$ and pneumonia $(\mathrm{n}=53 ; 8 \%)$.

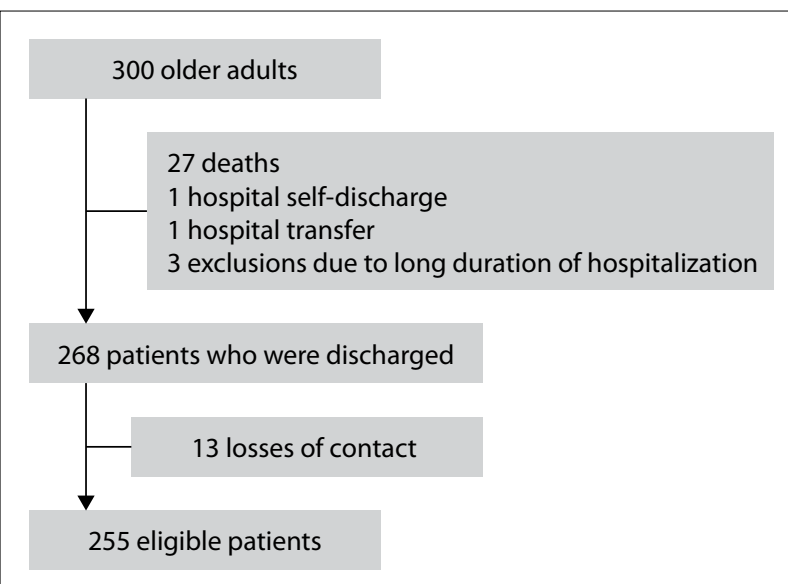

Figure 1. Study flowchart.

The frequency of polypharmacy was $68.2 \%$, and the number of medications used by these older adults was higher after discharge (median =6.0; IQR 4.0) than the total number of medications used before admission (median = 5.0; IQR 5.0). Potential drug interactions were identified in 173 patients $(67.8 \%)$, with a median of six interactions per older adult $(\mathrm{IQR}=4$; minimum $=1$, maximum $=15)($ Table 1$)$.

Overall, 266 types of potential drug interactions were observed, of which 145 (54.5\%) were classified as major, 116 (43.6\%) as moderate and five (1.9\%) as contraindicated. The most frequent major

Table 1. Sociodemographic, clinical and drug therapy-related characteristics of the sample of 255 older adults

\begin{tabular}{|c|c|}
\hline Characteristics & Value (\%) \\
\hline \multicolumn{2}{|l|}{ Sociodemographic characteristics } \\
\hline Age in years, median (IQR) & $75(13)$ \\
\hline Female gender, $\mathrm{n}(\%)$ & $146(57.3)$ \\
\hline \multicolumn{2}{|l|}{ Clinical characteristics } \\
\hline VES-13 score, median (IQR) & $5(6.0)$ \\
\hline Charlson Comorbidity Index, median (IQR) & $5(2.0)$ \\
\hline Internal medicine unit, $\mathrm{n}(\%)$ & $158(62.0)$ \\
\hline Geriatrics unit, $n$ (\%) & $97(38.0)$ \\
\hline Length of hospital stay, median (IQR) & $12(10)$ \\
\hline \multicolumn{2}{|l|}{ Functional characteristics } \\
\hline VES-13 score, median (IQR) & $5(6.0)$ \\
\hline \multicolumn{2}{|l|}{ Admission diagnoses, $\mathrm{n}(\%)$} \\
\hline Respiratory system diseases & $64(25.1)$ \\
\hline Genitourinary system diseases & $43(16.9)$ \\
\hline Circulatory system diseases & $30(11.8)$ \\
\hline $\begin{array}{l}\text { Symptoms, signs and abnormal clinical and laboratory } \\
\text { findings not elsewhere classified in ICD-10 codes R00-R99 }\end{array}$ & $25(9.8)$ \\
\hline Some infectious and parasitic diseases & $21(8.2)$ \\
\hline Digestive system diseases & $18(7.1)$ \\
\hline Mental and behavioral disorders & $14(5.5)$ \\
\hline Endocrine, nutritional and metabolic diseases & $11(4.3)$ \\
\hline Other* & $40(15.6)$ \\
\hline \multicolumn{2}{|l|}{ Comorbidities, n (\%) } \\
\hline Arterial hypertension & $181(70.9)$ \\
\hline Diabetes & $110(43.1)$ \\
\hline Pneumonia & $53(20.8)$ \\
\hline Chronic renal failure & $45(17.6)$ \\
\hline Hypothyroidism & $43(16.9)$ \\
\hline Heart failure & $38(14.9)$ \\
\hline \multicolumn{2}{|l|}{ Drug therapy-related characteristics } \\
\hline Polypharmacy, n (\%) & $174(68.2)$ \\
\hline Number of medicines used after discharge, median (IQR) & $6(4.0)$ \\
\hline Number of medicines used before admission, median (IQR) & $5(5.0)$ \\
\hline Patients with interactions, $\mathrm{n}(\%)$ & $173(67.8)$ \\
\hline Number of interactions per patient, median (IQR) & $6(4.0)$ \\
\hline Number of interactions per patient, minimum-maximum & $1(15)$ \\
\hline \multicolumn{2}{|c|}{$\begin{array}{l}\text { ICD-10 = International Classification of Diseases, tenth edition; }{ }^{*}=\text { Sum of } \\
\text { low-frequency admission diagnoses found in the study but not included } \\
\text { in the other categories shown in this table; IQR = interquartile range; } \\
\text { VES-13 = Vulnerable Elders Survey } 13 \text { : individuals with scores } \geq 3 \text { were } 4.2 \text { times } \\
\text { more likely to be at risk of functional decline within two years, compared with } \\
\text { individuals with lower scores. }{ }^{16}\end{array}$} \\
\hline
\end{tabular}


interaction in this study was between amlodipine and simvastatin, which was identified in 16 (6.3\%) of all the prescriptions. The ten most frequent major drug interactions and their clinical effects, as per DrugReax, are shown in Table 2.

The most common moderate interaction was between insulin and losartan, which was observed in the drug therapy prescribed for 17 patients $(6.7 \%)$. The most common moderate interactions identified in this study and their clinical consequences, as per DrugReax, are shown in Table 2.

Five types of contraindicated drug interactions were identified, from which the most frequent clinical effects were increased risk of QT prolonged interval (fluconazole plus salmeterol; and domperidone plus fluconazole), followed by increased risk of extrapyramidal reactions (bromopride plus venlafaxine) and increased risk of myopathy and rhabdomyolysis (ketoconazole plus simvastatin; and clarithromycin plus simvastatin).

Drug interactions that increase the risk of falls and fractures were the most frequent $(n=4)$ among those that should be avoided among older adults, as per the 2015 AGS/Beers criteria. Among the older people investigated here, three presented potential drug interactions between opioid receptor agonist analgesics and two or more drugs acting on the central nervous system (CNS). The potential drug interactions identified in this study, which should be avoided among older adults, as per the 2015 AGS/Beers criteria, are described in Table 3.

Table 4 shows the results from the univariate and multivariate analyses on the factors associated with occurrences of drug interactions. In the univariate analyses, statistically significant associations were found between drug interactions and polypharmacy $(\mathrm{P}=0.00)$

Table 2. Description of major and moderate drug interactions with frequencies higher than four in the drug therapy prescribed at hospital discharge among the 255 elderly subjects, and their clinical effects

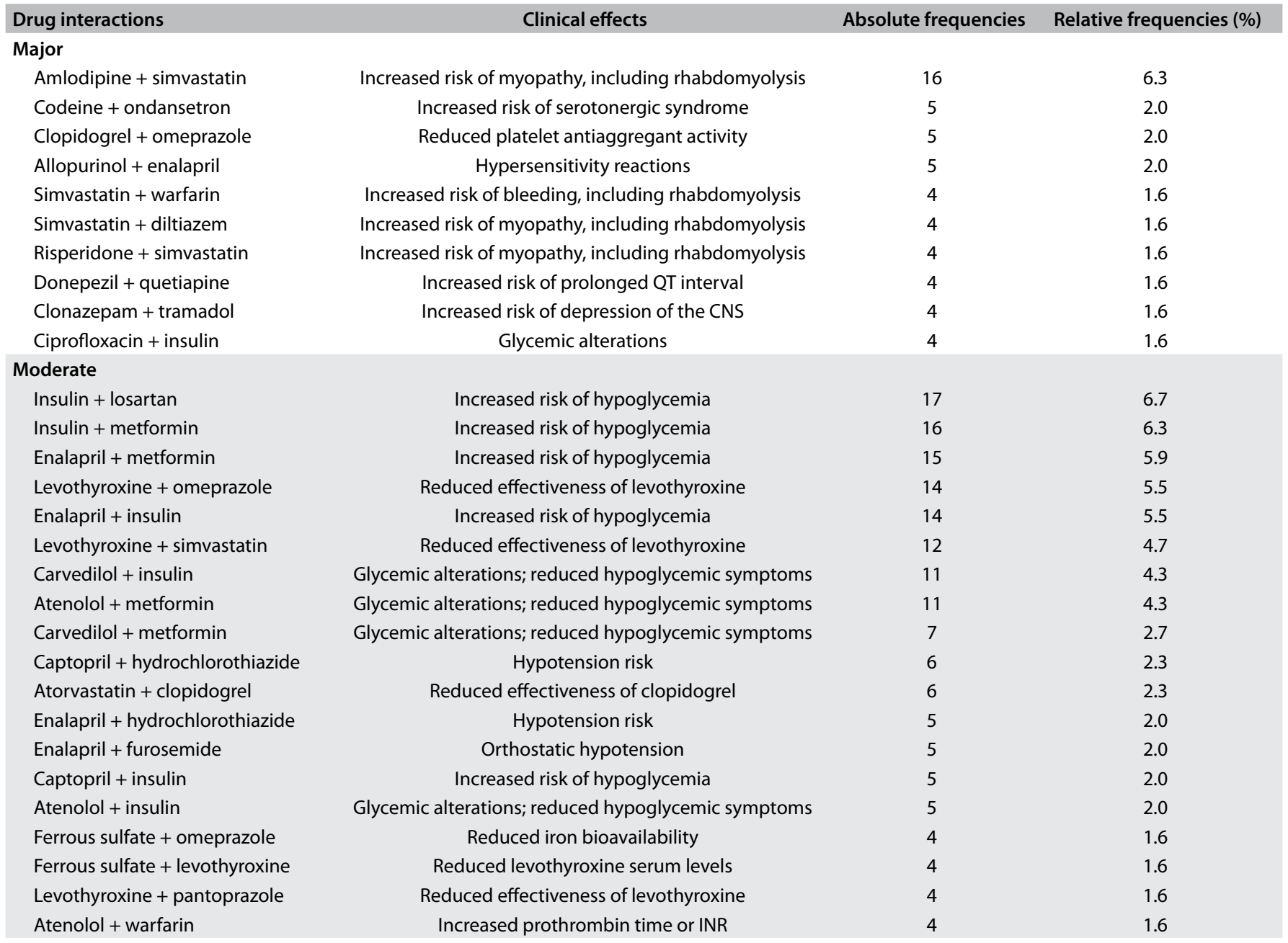

CNS = central nervous system; INR = international normalized ratio 
Table 3. Description of drug interactions that should be avoided among older adults, as per the 2015 American Geriatric Society (AGS)/ Beers criteria, in the drug therapy prescribed for older adults at hospital discharge

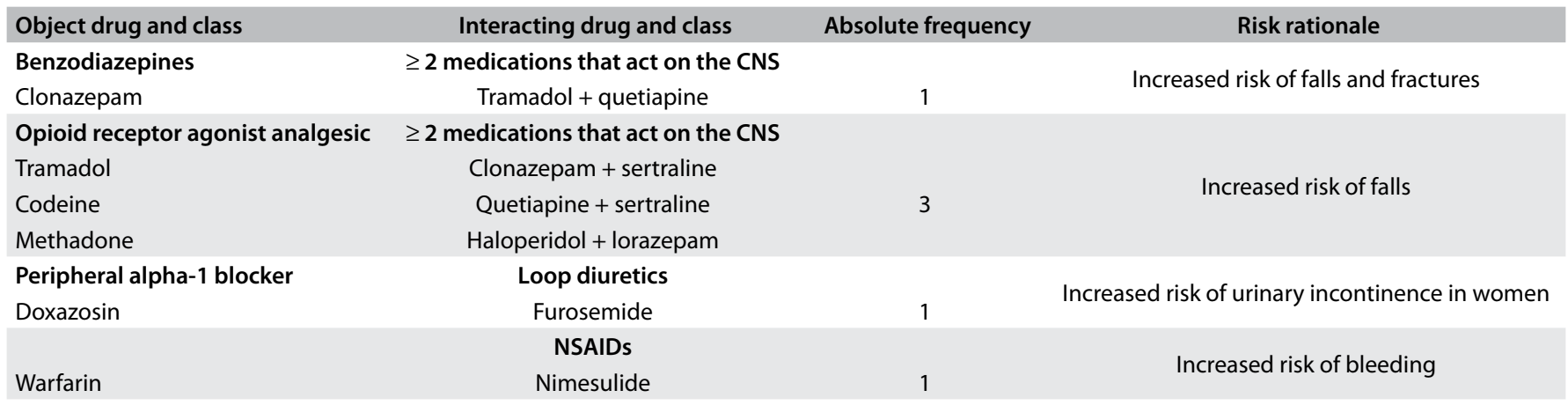

CNS = central nervous system; NSAIDs = nonsteroidal anti-inflammatory drugs.

Table 4. Univariate and multivariate analyses on factors associated with occurrences of drug interactions in the drug therapy prescribed for 255 older adults at hospital discharge

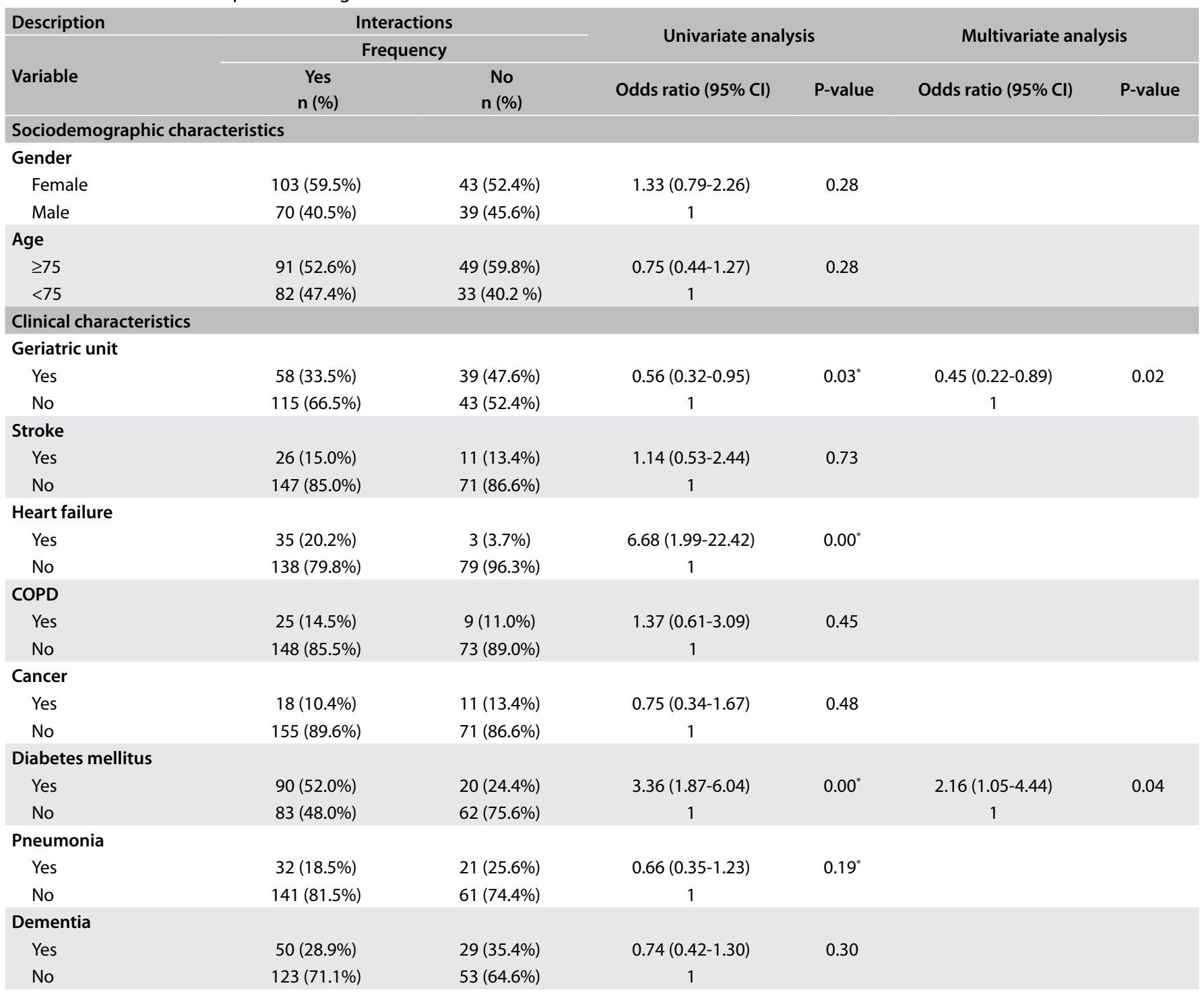


Table 4. Continuation

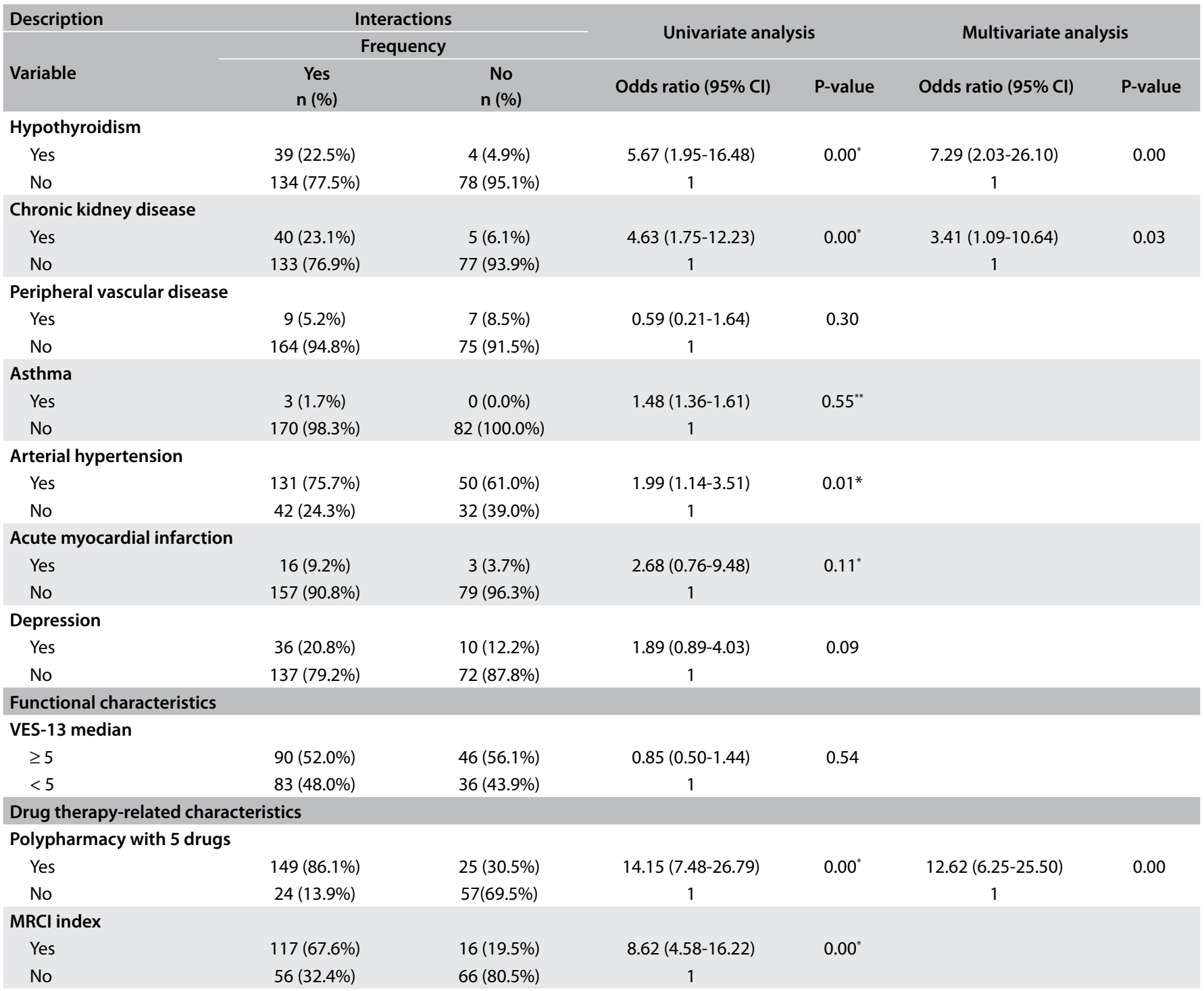

"P-value < 0.2: variable selected for the multivariate logistic regression; " ${ }^{*}$-value was calculated using Fisher's exact test; Hosmer-Lemeshow test: chi-square = 4.958; degrees of freedom $=7 ; P=0.665$.

$\mathrm{Cl}=$ confidence interval; $\mathrm{COPD}=$ chronic obstructive pulmonary disease; VES-13 = Vulnerable Elders Survey-13; MRCI= Medication Regimen Complexity Index.

and between drug interactions and high drug therapy complexity index $(P=0.00)$. In the multivariate analysis, the factors that remained associated with drug interactions were polypharmacy (odds ratio, $\mathrm{OR}=12.62$; 95\% confidence interval, CI 6.25-25.50; $\mathrm{P}=0.00)$, diabetes mellitus $(\mathrm{OR}=2.16 ; 95 \% \mathrm{CI} 1.05-4.44 ; \mathrm{P}=0.04)$, hypothyroidism $(\mathrm{OR}=7.29 ; 95 \% \mathrm{CI} 2.03-26.10 ; \mathrm{P}=0.00)$, chronic kidney disease $(\mathrm{OR}=3.41 ; 95 \% \mathrm{CI} 1.09-10.64 ; \mathrm{P}=0.03)$ and hospitalization in geriatric units $(\mathrm{OR}=0.45 ; 95 \% \mathrm{CI} 0.22-0.89 ; \mathrm{P}=0.02)$.

\section{DISCUSSION}

This study showed that potential drug interactions occurred very frequently in the drug therapy that was prescribed for older adults at discharge from hospital. This result is compatible with the findings from previous studies involving older patients at hospital discharge, which also showed high prevalence of drug interactions in this setting. ${ }^{17,18}$ The number of drugs prescribed was significantly associated with the number of drug interactions. Patients with diabetes mellitus, hypothyroidism or chronic kidney disease (CKD) also had more drug interactions than did those with other comorbidities. The frequency of drug interactions was lower among the older adults who had been hospitalized in the geriatric unit.

High prevalence $(54.5 \%)$ of major drug interactions was observed in this study. These can potentially increase the risks 
of cardiotoxicity, bleeding, rhabdomyolysis and hypoglycemia, which may compromise the functionality and quality of life of older people. ${ }^{9}$ As shown in previous studies, high frequency of potentially harmful drug interactions at hospital discharge was noted. Angiotensin-converting enzyme inhibitors (ACE inhibitors), diuretics, beta-blockers, antiplatelet agents, antidiabetics and oral anticoagulants were the drugs most involved in these interactions. ${ }^{18,19}$

Among the most common major drug interactions, the interaction between amlodipine and simvastatin was most prevalent. This drug interaction may increase the risks of rhabdomyolysis and myopathy. ${ }^{20,21}$ Combined therapies between statins and other cardiovascular medications are common, and the potential for significant drug interactions needs to be borne in mind, since such interactions increase the exposure to statins and, consequently, elevate the risk of myopathy. ${ }^{20-22}$

High prevalence of drug interactions with medications of the ACE inhibitor class was frequently observed in this study. Changes to renal function relating to aging increase the susceptibility of older adults to the nephrotoxic effects of ACE inhibitors, especially if administered with other medications. A prospective study in which the aim was to identify current drug-drug interaction (DDI) that resulted in adverse drug reactions among older patients within 30 days of discharge from an internal medicine clinic found that older adult patients who had been prescribed furosemide and ACE inhibitors presented asymptomatic elevated serum creatinine during the treatment and underwent dose adjustment of ACE inhibitors and diuretics. ${ }^{18}$

Studies on older patients receiving outpatient treatment have also identified high prevalence of concomitant use of ACE inhibitors and diuretics for blood pressure control. ${ }^{23,24}$ Despite the greater effectiveness of this combination of antihypertensives, the combination of these medications increases the risk of orthostatic hypotension, especially among older people, with a risk of injury due to falls. ${ }^{25}$

In a study conducted in the south of Brazil, the frequency with which patients used antidiabetics and antihypertensives was high, ${ }^{26}$ due to high prevalence of diabetes mellitus and arterial hypertension. While some interactions with antidiabetics are desirable and promote glycemic control in patients with diabetes, continuous blood glucose measurement should be performed to ensure that hypoglycemia does not occur in older adults. ${ }^{26}$ Hypoglycemic events among the elderly are associated with worsened cognitive decline and increased frequency of cardiovascular events. Furthermore, sarcopenia, peripheral neuropathy, dysautonomia and reduced visual acuity among older people elevate the risk and severity of falls, favored by episodic hypoglycemic events. ${ }^{27}$

Among the drugs for which concomitant prescriptions are contraindicated, those that had the clinical effect of increasing the risk of prolonged QT interval were observed more frequently.
Among the risk factors for this event were female sex, aging and a combination of drugs that alone prolong the QT interval or increase the likelihood of this event through inhibiting drug metabolism. This prolongation may trigger the onset of ventricular arrhythmias and result in sudden death, which highlights the importance of avoiding drug interactions that expose older adults to higher risk of prolonging the QT interval and the importance of monitoring patients in cases in which such combinations are necessary. ${ }^{25}$

One innovative approach in the present study comprised identification of drug interactions that should be avoided among older people, as per the $2015 \mathrm{AGS} /$ Beers criteria. The recommendations of these criteria stem from observation that these interactions are highly associated with clinically relevant adverse events among older adults. ${ }^{11}$

Associations that elevated the risk of falls were most frequent. Besides the clinical consequences, such as increased morbidity and mortality, falls among older people lead to social, economic and psychological harm, thereby increasing dependence and institutionalization..$^{28}$ An ecological study on fall-related admission and mortality rates among older adults showed that the mortality and hospitalization rates due to falls were higher among older people in Brazil. This emphasizes that use of three or more drugs acting on the central nervous system should be avoided in the geriatric population. $^{29}$

Occurrences of drug interactions were positively associated with the number of drugs used, which was in line with other published studies. ${ }^{30,31}$ A retrospective study in which the trends and determinants of polypharmacy among patients discharged from an internal medicine unit in a teaching hospital were measured showed that the risk factors for polypharmacy were age older than 75 years, high CCI and multiple morbidities. ${ }^{17}$ The presence of multiple morbidities in older adults favors prescription of several medications. Moreover, the widespread reality is that doctors do not have access to all the medicines that their patients are already using. This favors prescription of a more significant number of medications and highlights the importance of drug therapy reconciliation during the transition of care from the hospital setting to the patient's home. ${ }^{25}$

In addition to polypharmacy, the multivariate analysis identified that the factors relating to higher frequencies of drug interactions were diabetes mellitus, hypothyroidism and CKD. Regarding glycemic control among patients with diabetes, prescription of oral antidiabetics such as metformin, with or without associated prescription of insulin, may be necessary to improve the effectiveness of treatment. This may favor drug interactions among older adults, since the present study showed that metformin and insulin are medications often associated with potential drug interactions. Also, diabetes in older people is usually accompanied by cardiovascular 
complications and other comorbidities. ${ }^{27,32}$ Therefore, in this population, use of five or more medications is frequent and enables drug interactions. ${ }^{32}$

Regarding hypothyroidism, it is known that thyroid-related diseases are highly prevalent and occur more frequently among older women. ${ }^{33}$ The treatment indicated for this condition is based on replacement doses of levothyroxine sodium, a medication for which bioavailability is modified by drug interactions with ferrous sulfate and proton pump inhibitors. ${ }^{34}$ This may explain the positive association between hypothyroidism and drug interactions among the older adults investigated here.

Furthermore, it was observed that the elderly individuals with CKD had higher numbers of drug interactions. Patients with this disease are at high risk of metabolic and cardiovascular complications and, consequently, require use of polypharmacy, which is one of the factors involved in occurrences of drug interactions. ${ }^{35}$

Lastly, it was observed that hospitalization in the geriatric unit gave rise to lower likelihood of drug interactions at hospital discharge. Older individuals have particular health characteristics and specific medical needs that are more likely to be taken into consideration by geriatricians, who have specialized knowledge and skills. Geriatricians have greater awareness of the risks of adverse drug events among older adults and, therefore, during hospitalization. They can streamline the drug therapy strategy, including deprescription of medications, which may contribute towards lower levels of interactions. ${ }^{36}$

Given the high frequency of drug interactions and polypharmacy, there is an evident need for an approach that ensures safe drug therapy for older adults at discharge from hospital. The strategies that might be involved include analysis of the dose used, consideration of possible therapeutic alternatives and patient monitoring, along with the structuring of a multidisciplinary team composed of a geriatrician, a clinical pharmacist and a nurse. ${ }^{4,26}$ Interventions conducted by pharmacists within this practical setting, such as drug therapy reviews and actions planned with the prescriber, may reduce the number of older patients with clinicallyrelevant drug interactions. ${ }^{5}$

The strength of the present study lay in its use of software with sensitivity and specificity that were suitable for identifying drug interactions among older adults. However, this study had significant limitations. First, the sample was non-probabilistic, which may have compromised the external validity of the results found. Second, the study was conducted in a hospital that is not part of the Brazilian National Health System (Sistema Único de Saúde, SUS) and thus may not reflect the reality of most older people in Brazil. Also, this study focused on potential drug interactions and did not identify interactions with clinical manifestations. Furthermore, the durations of treatments were not considered in identifying drug interactions. Therefore, the frequency of drug interactions may have been overestimated, since some of these interactions need mechanisms for enzyme induction and inhibition that are time-dependent.

\section{CONCLUSIONS}

The frequency of potential drug interactions in the drug therapy prescribed to these older adults at discharge from hospital was high. Polypharmacy, diabetes mellitus, hypothyroidism and chronic kidney disease were positively associated with occurrences of potential drug interactions, and admission to a geriatric unit was inversely associated with such occurrences.

\section{REFERENCES}

1. Melo DO, Ribeiro E, Storpirtis S. Potential drug-drug interaction in a Brazilian teaching hospital: age-related differences? Rev Ciên Farm Básica Apl. 2015;36(3):435-44

2. Veras RP, Oliveira M. Aging in Brazil: the building of a healthcare model. Ciênc Saúde Coletiva. 2018;23(6):1929-36. PMID: 29972500; doi: 10.1590/1413-81232018236.04722018

3. Olsson IN, Runnamo R, Engfeldt P. Medication quality and quality of life in the elderly, a cohort study. Health and Quality of Life Outcomes. 2011;9(95). PMID: 22054205; doi: 10.1186/1477-7525-9-95

4. Rodrigues MCS, Oliveira C. Drug-drug interactions and adverse drug reactions in polypharmacy among older adults: an integrative review. Rev Latino-Am Enfermagem. 2016;24:e2800. PMID: 27598380; doi: 10.1590/1518-8345.1316.2800

5. RoblekT, Deticek A, Leskovar B, et al. Clinical-pharmacist intervention reduces clinically relevant drug-drug interactions in patients with heart failure: a randomized, double-blind, controlled trial. Int J Cardiol. 2016;203:647-52. PMID: 26580349; doi: 10.1016/j. ijcard.2015.10.206.

6. Hines LE, Murphy JE. Potentially harmful drug-drug interactions in the elderly: a review. Am J Geriatr Pharmacother. 2011;9(6):364-77. PMID: 22078863; doi: 10.1016/j.amjopharm.2011.10.004

7. Lucas C, Byles J, Martin JH. Medicines optimisation in older people: taking age and sex into account. Maturitas. 2016;93:114-20. PMID: 27506133; doi: 10.1016/j.maturitas.2016.06.021.

8. Cortejoso L, Dietz RA, Hoffman G, Gosch M, Sattler A. Impact of pharmacist interventions in older patients: a prospective study in a tertiary hospital in Germany. Clin Interv Aging. 2016;11:1343-50. PMID: 27713625; doi: 10.2147/CIA.S109048

9. IBM Micromedex ${ }^{\circledR}$ DRUGREAX ${ }^{\circledR}$ (electronic version). Truven Health Analytics, Greenwood Village, Colorado, USA. Available from: https:// www.micromedexsolutions.com/micromedex2/librarian/ssl/true Accessed in 2019 (Aug 28).

10. Guedes TM, Reis AMM. Performance of three brands of drug interaction programs for use in geriatrics. Pharmacoepidemiology Drug Saf. $2013 ; 22: 489$ 
11. American Geriatrics Society. American Geriatrics Society 2015 Updated Beers Criteria for Potentially Inappropriate Medication Use in Older Adults. J Am Geriatr Society. 2015;63(11):2227-46. PMID: 26446832; doi: $10.1111 /$ jgs. 13702 .

12. Busca por Codigo. [CID10 - Classificação Estatística Internacional de Doenças e Problemas Relacionados com a Saúde, $10^{a}$ edição.] Available from: https://www.cid10.com.br/. Accessed in 2019 (Sep 4).

13. Charlson ME, Pompei P, Ales KL, Mackenzie CR. A new method of classifying prognostic comorbidity in longitudinal studies: development and validation. J Chronic Dis. 1987;40(5):373-83. PMID: 3558716.

14. Melchiors AC, Correr CJ, Fernández-Llimos F. Tradução e validação para o português do Medication Regimen Complexity Index. Arq Bras Cardiol. 2007;89(4):210-8. PMID: 17992376.

15. Pantuzza LLN, Ceccato MCB, Silveira MR, Pinto IV, Reis AMM. Validation and standardization of the Brazilian version of the Medication Regimen Complexity Index for older adults in primary care. Geriatr Gerontol Int. 2018;18(6):853-9. PMID: 29380500; doi: 10.1111/ggi.13261.

16. Luz LL, Santiago LM, Silva JF, Mattos IE. Psychometric properties of the Brazilian version of the Vulnerable Elders Survey-13 (VES-13). Cad Saúde Pública. 2015;31(3):507-15. PMID: 25859718.

17. Abolhassani N, Castioni J, Santschi V, Waeber G, Marques-Vidal P. Trends and Determinants of Polypharmacy and Potential Drug-Drug Interactions at Discharge from Hospital Between 2009-2015. J Patient Saf. 2018. PMID: 29557932; doi: 10.1097/PTS.0000000000000482.

18. Marusic S, Bacic-Vrca V, Neto PR, et al. Actual drug-drug interactions in elderly patients discharged from internal medical clinic: a prospective observational study. Eur J Clin Pharmacol. 2013;69:1717-24. PMID: 23739998; doi: 10.1007/s00228-013-1531-7.

19. Bertoli R, Bissig M, Caronzolo D, et al. Assessment of potential drug-drug interactions at hospital discharge. Swiss Med Wkly. 2010;15,140:w13043. PMID: 20373176; doi: 10.4414/smw.2010.13043.

20. Chatzizisis YS, Koskinas KC, Misirli G, et al. Risk factors and drug interactions predisposing to statin-induced myopathy: implications for risk assessment, prevention and treatment. Drug Saf. 2010;33(3):171-87. PMID: 20158283; doi: 10.2165/11319380-000000000-00000

21. Wiggins BS, Saseen JJ, Page RL $2^{\text {nd }}$, et al. Recommendations for Management of Clinically Significant Drug-Drug Interactions With Statins and Select Agents Used in Patients With Cardiovascular Disease: A Scientific Statement From the American Heart Association. Circulation. 2016; 134:e468-95. PMID: 27754879; doi: 10.1161/ CIR.0000000000000456.

22. Thai $M$, Reeve $E$, Hilmer $S N$, et al. Prevalence of statin-drug interactions in older people: a systematic review. Eur J Clin Pharmacol. 2017;72(5):51321. PMID: 26790666; doi: 10.1007/s00228-016-2011-7.

23. Novello MF, Rosa ML, Ferreira RT, et al. Compliance with the Prescription of Antihypertensive Medications and Blood Pressure Control in Primary Care. Arq Bras Cardiol. 2017;108(2):135-42. PMID: 28327875 ; doi: 10.5935/ abc.20170009.
24. Luppen LS, Sampaio FH, Zandoná B, et al. Prevalência do uso de antihipertensivos em pacientes acompanhados em Unidade Básica de Saúde, Canoas, RS, Brasil. Rev AMRIGS. 2011;55(1):42-7.

25. Day RO, Snowden L, McLachlan AJ. Life-threatening drug interactions: what the physician needs to know. Intern Med J. 2017:47(5):501-12. PMID: 28503886; doi: 10.1111/imj.13404.

26. Amaral DMD, Perassolo MS. Possíveis interações medicamentosas entre os anti-hipertensivos e antidiabéticos em participantes do Grupo HIPERDIA de Parobé, RS (Uma análise teórica). Rev Ciên Farm Básica Apl. 2012;33(1):99-105. Available at: http://serv-bib.fcfar.unesp.br/seer/index. php/Cien_Farm/article/view/1703/1703. Accessed in 2019 (Aug 18).

27. Inzucchi SE, Bergenstal RM, Buse JB, et al. Management of hyperglycemia in type 2 diabetes, 2015: a patient-centered approach: update to a position statement of the American Diabetes Association and the European Association for the Study of Diabetes. Diabetes Care. 2015;38(1):140-9. PMID: 25538310; doi: 10.2337/dc14-2441.

28. Maia BC, Viana PS, Arantes PMM, Alencar MA. Consequências das quedas em idosos vivendo na comunidade. Rev Bras Geriatr Gerontol. 2011;14(2):381-93

29. Abreu DROM, Novaes ES, Oliveira RR, Mathias TAF, Marcon SS. Fall-related admission and mortality in older adults in Brazil: trend analysis. Ciênc Saúde Colet. 2018;23(4):1131-41. PMID: 29694573; doi: 10.1590/141381232018234.09962016

30. Ahmad A, Mast MR, Nijpels G, et al. Identification of drug-related problems of elderly patients discharged from hospital. Patient Prefer Adherence. 2014;8:155-65. PMID: 24523581; doi: 10.2147/PPA.S48357.

31. Pinto NBF, Vieira LB, Pereira FMV, Reis AMM, Cassiani SHB. Interações medicamentosas em prescrições de idosos hipertensos: prevalência e significância clínica [Drug interactions in prescriptions for elderly hypertensive patients: prevalence and clinical significance.] Rev Enfermagem UERJ. 2014;22(6):735-41. doi: https://doi.org/10.12957/ reuerj.2014.7111. Available at: https://www.e-publicacoes.uerj.br/index. php/enfermagemuerj/article/view/7111. Accessed in 2019 (Aug 18).

32. Prado MA, Francisco PM, Barros MB. Diabetes in the elderly: drug use and the risk of drug interaction. Ciênc Saúde Colet. 2016;21(11):3447-58. PMID: 27828578; doi: 10.1590/1413-812320152111.24462015.

33. Bensenor IM, OImos RD, Lotufo PA. Hypothyroidism in the elderly: diagnosis and management. Clin Interv Aging. 2012;7:97-111. PMID: 22573936; doi: 10.2147/CIA.S23966.

34. Liwanpo L, Hershman JM. Conditions and drugs interfering with thyroxine absorption. Best Pract Research Clin Endocrinol Metab. 2009;23(6):781-92. PMID: 19942153; doi: 10.1016/j.beem.2009.06.006.

35. Lassiter J, Bennett WM, Olyaei AJ. Drug dosing in elderly patients with chronic kidney disease. Clin Geriatr Med. 2013;29(3):657-705. PMID: 23849014; doi: 10.1016/j.cger.2013.05.008.

36. Petrovic M, Sommers A, Onder G. Optimization of Geriatric Pharmacotherapy: Role of Multifaceted Cooperation in the Hospital Setting. Drugs Aging. 2016;33(3):179-88. PMID: 26884392; doi: 10.1007/ s40266-016-0352-7. 
Acknowledgements: This study received support from Fundação de Apoio à Pesquisa do Estado de Minas Gerais (FAPEMIG) and from the Pro-Rectorate for Research of Universidade Federal de Minas Gerais (UFMG)

Sources of funding: This study received support from Fundação de Apoio à Pesquisa do Estado de Minas Gerais (FAPEMIG), under protocol number PROBIC/FAPEMIG 2018, and from the Pro-Rectorate for Research of Universidade Federal de Minas Gerais (UFMG), under protocol number PRPqUFMG042018

Conflict of interest: There were no conflicts of interest to declare

Date of first submission: April 13, 2019

Last received: April 13, 2019

Accepted: July 5, 2019

\section{Address for correspondence:}

Adriano Max Moreira Reis

Faculdade de Farmácia, Universidade Federal de Minas Gerais (UFMG)

Av. Presidente Antônio Carlos, 6.627

Pampulha - Belo Horizonte (MG) — Brasil

CEP 31270-901

Tel. (+55 31) 3409-6943

E-mail: amreis@outlook.com 